DOI: 10.2478/romneu-2014-0013

\title{
Kernohan-Woltman notch phenomenon and intention tremors in case of chronic subdural hematoma
}

\author{
P. Sasikala ${ }^{1}$, Bindu Menon ${ }^{2}$, Amit Agarwal $^{3}$ \\ Narayana Medical College Hospital, Chinthareddypalem, Nellore, Andhra Pradesh (India) \\ ${ }^{1}$ Assistant Professor of Physiology, Department of Physiology \\ ${ }^{2}$ Professor of Neurology, Department of Neurology \\ ${ }^{3}$ Professor of Neurosurgery, Department of Neurosurgery
}

\begin{abstract}
Movement disorders are atypical and rare presentation of chronic subdural hematomas. We report a case of 60 year man who presented with intention tremors and altered sensorium. The patient had Kernohan-Woltman notch phenomenon on clinical examination. CT scan brain showed a large left fronto-temporo-parietal chronic subdural hematoma with significant mass effect and midline shift. His symptoms relieved completely after surgical evacuation of the hematoma.
\end{abstract}

Key words: Chronic subdural hematoma, Kernohan-Woltman notch, tremors, intention tremor.

\section{Introduction}

Chronic subdural hematomas $(\mathrm{CSDH})$ can present with a wide variety of symptoms, however movement disorders (the most common is secondary Parkinsonism) in CSDH are atypical and rare presentations. (1, 2) KernohanWoltman notch phenomenon appears when any supratentorial mass lesion cause the midline shift and there is compression of the cerebral peduncle against the tentorial edge ipsilateral hemiparesis or hemiplegia and mydriasis. (3-5) The appearance of Kernohan-Woltman notch phenomenon has rarely been reported in patients with CSDH. (4-7) In present article we report an extremely rare presentation as intention tremors and Kernohan-Woltman notch phenomenon that resolved after surgical evacuation.

\section{Case report}

A 60-year-old man presented with progressive stiffness and weakness of all four limbs (left more than right), abnormal movements of right upper limb and altered senosirum of two days duration. There was not history of fall. There was no past history of diabetes or hypertension. He had pulse rate of 50 per minute. Other general and systemic examination was unremarkable. On neurological examination he was in altered sensorium. Tone was increased in all four limbs. There was weakness of grade 0/5 of left upper 
and lower limbs. He was localizing with right upper limb. All the deep tendon reflexes were brisk and planters were extensor. There was mild papillary asymmetry (left $>$ right) but both were reacting to light. He had irregular low frequency tremor those were becoming grossly uncontrollable with these attempted movements (Video-1). Routine hematological and biochemical investigations were within normal limits. CT brain plain showed a largely hyperdense collection with layering over left fronto-temporo-parietal region with significant mass effect and midline shift (Figure 1). He underwent left frontal and temporal burr hole under local anesthesia and evacuation of chronic subdural hematoma. He made significant improvement over next 24 hours in his sensorium. He regained consciousness, his weakness improved and abnormal movements disappeared over next 48 hours (Video-2).

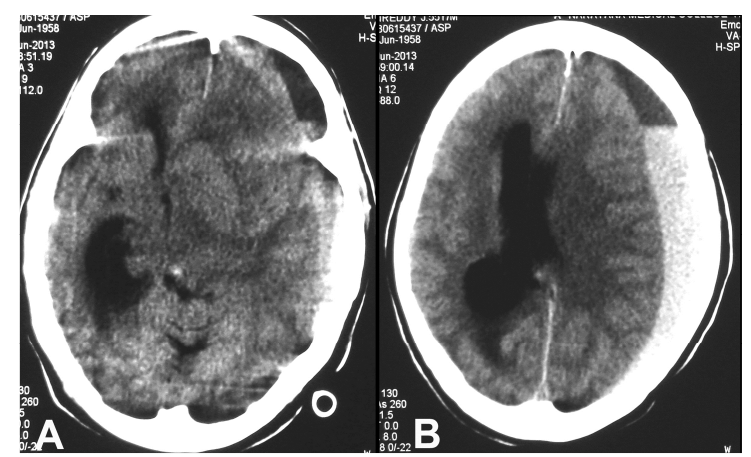

Figure 1

CT brain plain showing a largely hyperdense collection with layering over left fronto-temporoparietal region with significant mass effect and midline shift

\section{Discussion}

Sudden onset of movement disorder in the elderly patients requires prompt radiological investigations to rule out treatable causes of these dysfunctions. (2) Movement disorders in CSDH patients probably caused by a pressure effect on basal ganglia structures $(8,9)$ or by altering the function of neurotransmitters. (9) compression of midbrain (interfere nigro-striatal dopaminergic transmission) (10) and compression of anterior choroidal artery (11) However in contrast to the resting tremors of the Parkinsonism (12, 13) the present patient had intention tremors. Intention tremors are mainly occurs in cerebellar disorders, characterized as a kinetic tremor with a prominent intention component and the ipsilateral extremity is involved when a cerebellar hemisphere in involved. $(14,15)$ Also as the cerebellum is connected to contralateral thalamus and cortex, both cerebellar lesions and contralateral thalamocortical lesions can result in cerebellar dysfunction. $(15,16)$ It has been suggested that the cerebellum, superior cerebellar peduncles, red nucleus, and thalamus can be involved in the generation of intentions tremors and the modulation of cerebello-thalamic projections has been shown to improve the tremors. $(17,18)$ On imaging studies atrophic structures or changes in signal intensity has been demonstrated in the cerebello-rubral thalamic tract and the etiological significance of the tract has been confirmed as the mechanism of the 
DOI: 10.2478/romneu-2014-0013

intention tremors. (19) Direct pressure on or invasion of deep basal ganglonic structures and brain stem compression due to upward or downward herniations which displaces the midbrain against the tentorial edge $(20,21)$ could be responsible not only for the tremors but also for the hemiparesis. Hemiparesis can be found in up to $58 \%$ of cases of CSDH and mostly the deficit is contralateral to the lesion (direct pressure on the cerebral hemisphere). (22) In rare circumstances the focal neurological deficit can be ipsilateral to CSDH. $(5,22)$ Our patient had ipsilateral weakness, abnormal movements in the upper limb, marginal asymmetry of the pupils, a finding consistent with Kernohan-Woltman notch phenomenon. $(3,5)$ Apart from that the prompt evacuation leads to complete reversal of Kernohan-Woltman notch phenomenon and complete recovery of motor functions. (4-6)

Address for correspondence:

Dr. Amit Agrawal

Professor of Neurosurgery

Department of Neurosurgery

Narayana Medical College Hospital

Chinthareddypalem

Nellore-524003

Andhra Pradesh (India)

Email-dramitagrawal@gmail.com

dramit_in@yahoo.com

Mobile- +91-8096410032

\section{References}

1. Bostantjopoulou S, Katsarou Z, Michael M, Petridis A. Reversible parkinsonism due to chronic bilateral subdural hematomas. Journal of clinical neuroscience: official journal of the Neurosurgical Society of Australasia 2009;16:458-460.

2. Gelabert-Gonzalez M, Serramito-Garcia R, AranEchabe E. Parkinsonism secondary to subdural haematoma. Neurosurgical review 2012;35:457-460; discussion 460-451.

3. KERNOHAN JW, WOLTMAN HW. Incisura of the crus due to contralateral brain tumor. Archives of Neurology and Psychiatry 1929;21:274.

4. Moon K-S, Lee J-K, Joo S-P, et al. Kernohan's notch phenomenon in chronic subdural hematoma: MRI findings. Journal of clinical neuroscience: official journal of the Neurosurgical Society of Australasia 2007;14:989992.

5. Albayrak S, Ucler N, Ayden O, Cakin H. KernohanWoltman Notch Phenomenon Related to Chronic Subdural Hematoma: A Case Report. Journal of Medical Cases 2012;3:20-22.

6. Itoyama Y, Fujioka S, Ushio Y. Kernohan's notch in chronic subdural hematoma: findings on magnetic resonance imaging. Journal of neurosurgery 1995;82:645-646.

7. Yamasaki F, Kodama Y, Hotta T, Yuki K, Taniguchi E, Hashizume A. [Magnetic resonance imaging of Kernohan's notch in chronic subdural hematoma]. No to shinkei $=$ Brain and nerve 1997;49:563-566.

8. García de Y'ebenes J, Gervas JJ, Iglesias J, Mena MA, Martín del Rio R, Somoza E. Biochemical findings in a case of parkinsonism secondary to brain tumor. Annals of neurology 1982;11:313-316.

9. Sandyk R, Kahn I. Parkinsonism due to subdural hematoma. Case report. Journal of neurosurgery 1983;58:298-299.

10. Ling MJ, Aggarwal A, Morris JGL. Dopa-responsive parkinsonism secondary to right temporal lobe haemorrahage. Movement disorders: official journal of the Movement Disorder Society 2002;17:402-404.

11. Kotagal S, Shuter E, Horenstein S. Chorea as a manifestation of bilateral subdural hematoma in an elderly man. Archives of neurology 1981;38:195.

12. Chou SM, Gutmann L. Deteriorating parkinsonism and subdural hematomas. Neurology 2001;57:1295.

13. Sandyk R. Parkinsonism caused by chronic subdural haematoma. A case report. South African medical journal = Suid-Afrikaanse tydskrif vir geneeskunde 1982;61:595-596.

14. Chou K. Diagnosis and management of the patient with tremor. Medicine and health, Rhode Island 2004;87:135. 
15. Crawford P, Zimmerman EE. Differentiation and diagnosis of tremor. American Family Physician 2011;83:697.

16. Jankovic J, STANLEY F. Physiologic and Pathologic TremorsDiagnosis, Mechanism, and Management. Annals of internal medicine 1980;93:460-465.

17. Herzog J, Hamel W, Wenzelburger R, et al. Kinematic analysis of thalamic versus subthalamic neurostimulation in postural and intention tremor. Brain: a journal of neurology 2007;130:1608-1625.

18. Hamel W, Herzog J, Kopper F, et al. Deep brain stimulation in the subthalamic area is more effective than nucleus ventralis intermedius stimulation for bilateral intention tremor. Acta neurochirurgica 2007;149:749-758; discussion 758.
19. Fukuhara $\mathrm{T}$, Gotoh $\mathrm{M}$, Asari $\mathrm{S}$, Ohmoto $\mathrm{T}$. Magnetic resonance imaging of patients with intention tremor. Computerized medical imaging and graphics: the official journal of the Computerized Medical Imaging Society 1994;18:45-51.

20. Oliver L. Parkinsonism due to midbrain compression. Lancet 1959;2:817.

21. Polyzoidis K, McQueen J, Rajput A, MacFadyen D. Parkinsonism as a manifestation of brain tumor. Surgical neurology 1985;23:59-63.

22. Luxon LM, Harrison MJ. Chronic subdural haematoma. The Quarterly journal of medicine 1979; 48:43-53. 